\title{
Day time variations in noise levels at major crossings of J ammu city, India
}

\author{
Raj K umar Rampal*, SumitK otwal and Ranbir Singh J asrotia \\ Department of Environmental Sciences, University of Jammu, Jammu (J\&K), INDIA \\ * Corresponding author. E-mail: rajkrampal@ gmail.com
}

\begin{abstract}
The present study has been carried to assess Equivalent noise level $\left(\mathrm{L}_{\mathrm{eq}}\right)$, Noise climate $(\mathrm{NC})$, Traffic noise index (TNI) and Day Time Average Noise level from7.00 A.M. to 9.00 P.M $\left(\mathrm{L}_{d}\right)$ at eleven major crossings of Jammu City. The $L_{e q}$ and $L_{d}$ values at all the sites were observed to be above permissible limits prescribed by CPCB. The calculated values of $L_{d}$ at all the sites were observed to be statistically significant at 0.05 (5\%) level of significance $(\mathrm{p}=0.000-0.004)$.
\end{abstract}

Keywords: Noise pollution, Traffic noise, Major crossings, $\left(\mathrm{L}_{\mathrm{d}}\right)$ Day time average noise level, (TNI) Traffic noise index

\section{INTRODUCATION}

Transportation noise is a key problem in the cities of the world today. Noise from road vehicles produces disturbance to people more than from any other source of noise and has been increasing very fast over the last few decades. Traffic noise is created by a continuous flow of auto-vehicles and is generated by engines in jets, motor in trucks and contact of tyres on roads and wheels on rails. This affects not only those persons who live adjacent to roads, but also the occupants of the transportation means as well. On any road there is a general noise level as long as any traffic is moving. This general noise level varies with traffic density and time of the day. Distinctive and regular peaks in the noise level occur in the morning and evening as people travel to and from schools and work places (Ahmad and Khan, 2003). Further that no regulation is observed in blowing horns and use of defective silencers. Sometimes, people even use their vehicles without silencer pipes, which generate highly intolerable noise. Motor cycles, with their exposed engines and inadequately silencing arrangement, too, are notorious noise producers. Vehicles on roads produce irritation and it has been increasing over the years continuously due to steady increase in the number of vehicles and road traffic density. Sometimes fast moving heavy vehicles plying on public roads too, damage building structures. The noise may cause depreciation of the residential property located nearby highways and other noise prone places. The present study has been carried out to assess Equivalent noise level $\left(\mathrm{L}_{\mathrm{eq}}\right)$, Noise climate (NC), Traffic noise index (TNI) and Day Time Average Noise level from7.00 A.M. to 9.00 P.M $\left(\mathrm{L}_{\mathrm{d}}\right)$ at major crossings of Jammu city, J\&K.

\section{MATERIALS AND METHODS}

Study area: The study area has been divided into XI sites: Site-I (Janipur Crossing): The crossing forms the centre point of Bus Stand-Bantalab, Parade-Janipur Colony, Bus stand-Kot bhalwal and Bagh-e-Bahu-Janipur Colony traffic routes. Site-II (Ambphalla Crossing): This crossing lies on the Jammu-Srinagar National Highway I-A. Various vehicles going to different parts of the city pass through this crossing. Site-III (Rehari Crossing): This crossing on National Highway (I-A) lies next to Ambphalla crossing towards Bus stand. Various public and private vehicles going to Rajpura, Parade, Bantalab, Janipur etc. pass through this crossing. Site-IV (Kachi Chawani Crossing): This crossing lies in the heart of the city. Kachi Chawani is a hub of various coaching institutes. This zone forms the main focal point of the commercial activity in the Jammu city. Site-V (Parade Crossing): This forms the central point of all important traffic routes connecting different parts of the Jammu city such as Kachi Chawani, Bus Stand, Talab Tillo, Gandhi Nagar, Trikuta Nagar, Bagh-e-Bahu temple, Railway station etc. It is main centre of entry to vegetable market, fruit market and conventional commercial activity. Site-VI (Indira crossing): This site is located near Bus Stand. This crossing connects Shalamar, Hari Market, Gumat, Bus Stand and K.C. Chowk. Site-VII (Jewel Crossing): It is one of the busiest crossings of Jammu city. The traffic routes to Talab Tillo, Gumat, Bus Stand, Satwari pass through this crossing. Site-VIII (Vikram Crossing): This crossing connects old Jammu city with New Jammu city and lies on NH-IA. Traffic routes like Muthi-Bagh-e-Bahu temple, Janipur-Satwari, AmbphallaChanni, Parade-Railway station, Ambphalla-Airport, 
Parade-Gandhi Nagar pass through this crossing. SiteIX (Panama Crossing): This crossing is without commercial activity and lies on outskirts of Jammu. Traffic routes to Railway station, Channi, Narwal Mandi, Greater Kailash go via this crossing. Site- $X$ (Satwari Crossing): This crossing lies on NH-IA. Public and private vehicles plying to Pathankot via Samba, Kathua, and to Airport follow this traffic crossing. Site-XI (Gole Market crossing): This lies in Gandhi Nagar commercial area. It is the heart of the well planned part of the Jammu city. It is also regarded as the managed commercial hub of the Jammu city.

The measurement of sound pressure levels at each crossing were carried out at an interval of one hour from 7.00 A.M.-9.00 P.M. hours with the help of Sound level meter Model-8928 at ' $A$ ' weightage. During each sampling of noise, 20 readings of SPL were recorded at an interval of 30 seconds in a period of 10 minutes. The $\mathrm{L}_{\mathrm{eq}}$ was calculated by using the formula:-

$\mathrm{L}_{\text {eq }}=10 \log \left(\sum_{\mathrm{i}=1}^{\mathrm{n}=0} \mathrm{fi}\left(10^{\mathrm{L} / 10}\right) \mathrm{dB}(\mathrm{A})\right.$

Where, fi=fraction of time for which the constant sound level persists, $\mathrm{i}=$ time intervals, $\mathrm{n}=$ number of observations, $\mathrm{Li}=$ sound intensity at a time interval.

Noise Climate (NC) the range over which the sound levels are fluctuating in an interval of time and were calculated by following relation: $\mathrm{NC}=\mathrm{L}_{10}-\mathrm{L}_{90}$, where $\mathrm{L}_{10}=$ the noise level exceeding $10 \%$ of the time and $\mathrm{L}_{90}=$ the noise level exceeding $90 \%$ of the time.

Traffic Noise Index $(\mathrm{TNI})=4 *\left(\mathrm{~L}_{10}-\mathrm{L}_{90}\right)+\left(\mathrm{L}_{90}-30\right)$

Where, $30=$ correction factor.

$\mathrm{L}_{d}$ (Day Time Average Noise level) was calculated by applying the formula:

$$
\left.L_{d}=10 \log \left\{1 / 15 \sum_{i=1}^{15}\left(10^{\text {Leq } / 10}\right)\right]\right\}
$$

\section{RESULTS AND DISCUSSION}

The analysis of data of the $\mathrm{L}_{\mathrm{eq}}(\mathrm{dB} A)$ of the Crossings on the National Highway revealed that Rehari crossing exhibited minimum $\mathrm{L}_{\mathrm{eq}}$ of $66.9 \mathrm{~dB}(\mathrm{~A})$ at $7.00 \mathrm{~A} . \mathrm{M}$ while Jewel crossing exhibited maximum $\mathrm{L}_{\mathrm{eq}}$ of $87.5 \mathrm{~dB}(\mathrm{~A})$ at 2.00 P.M. But the average $\mathrm{L}_{\text {eq }}$ on the average crossing located at National highway was observed to range from $70.0 \mathrm{~dB}(\mathrm{~A})$ to $82.3 \mathrm{~dB}(\mathrm{~A})$ whereas the analysis of data of the $\mathrm{L}_{\mathrm{eq}}(\mathrm{dB} A)$ of the Crossings away from the National Highway revealed minimum $\mathrm{L}_{\mathrm{eq}}$ of $66.2 \mathrm{~dB}$ (A) at Gole Market crossing at 7.00 A.M and maximum $\mathrm{L}_{\mathrm{eq}}$ of $92.2 \mathrm{~dB}$ (A) at Kachi Chawani crossing at 2.00 P.M. The average crossing located away from National highway exhibited Avg. $\mathrm{L}_{\text {eq }}$ in the range of $69.0 \mathrm{~dB}(\mathrm{~A})$ to $84.9 \mathrm{~dB}(\mathrm{~A})$ (Table I). The analysis revealed that crossing located away from National highway within the city exhibited higher values of $\mathrm{L}_{\mathrm{e}}$. These higher values correspond with increase in commercial activity, traffic flow rate, opening of shops, institutes etc. Dhillon etal. (1994) also observed maximum noise level only at Chaura Bazaar (Ludhiana) when the commercial activity was at its peak and before 10.00 a.m. $\mathrm{L}_{\mathrm{eq}}$ was observed to be minimum due to low commercial activity.

The analysis of data of the Noise Climate (NC) of the Crossings on the National Highway revealed that Ambphalla crossing exhibited minimum NC of $13.2 \mathrm{~dB}$ (A) at 10.00 A.M while Rehari crossing exhibited maximum NCof $25.4 \mathrm{~dB}$ (A) at 8.00 A.M. But the average $\mathrm{NC}$ on the average crossing located at National highway was observed to range from $13.9 \mathrm{~dB}(\mathrm{~A})$ to $20.2 \mathrm{~dB}(\mathrm{~A})$ whereas the analysis of data of the $\mathrm{NC}(\mathrm{dB} \mathrm{A})$ of the Crossings away from the National Highway revealed minimum NC of $8.8 \mathrm{~dB}(\mathrm{~A})$ at Kachi Chawani crossing at 6.00 P.M and maximum NC of $23.8 \mathrm{~dB}$ (A) at Parade crossing at 2.00 P.M. The average crossing located away from National highway exhibited Avg. NC in the range of $12.1 \mathrm{~dB}(\mathrm{~A})$ to $22.6 \mathrm{~dB}$ (A) (Table II). The analysis of data of the Traffic Noise Index (TNI) (dB A) of the Crossings on the National Highway revealed that Ambphalla crossing exhibited minimum TNI of $93.5 \mathrm{~dB}(\mathrm{~A})$ at 10.00 A.M while Rehari crossing exhibited maximum TNI of $128.8 \mathrm{~dB}(\mathrm{~A})$ at $9.00 \mathrm{~A}$.M. This was due to the fact that Ambphalla crossing lies on the terminal part of the city with less traffic flow rate as compared with that of Rehari crossing which lies in the thickly populated area of Jammu and is always infested with heavy traffic. But the average TNI on the average crossing located at National highway was observed to range from $99.4 \mathrm{~dB}(\mathrm{~A})$ to $113.0 \mathrm{~dB}(\mathrm{~A})$ whereas the analysis of data of the TNI ( $\mathrm{dB} A)$ of the Crossings away from the National Highway revealed minimum TNI of $90.2 \mathrm{~dB}(\mathrm{~A})$ at Kachi Chaw ani crossing at 12.00 P.M and maximum TNI of $132.2 \mathrm{~dB}$ (A) at Indira crossing at 7.00 A.M because this crossing act as a temporary bus stand in the morning for various long route luxury buses within the state as well as interstate. More over a temporary vegetable mobile market at this crossing in the morning also become a source of public crowd. The average crossing located away from National highway exhibited Avg. TNI in the range of $97.9 \mathrm{~dB}(\mathrm{~A})$ to $113.3 \mathrm{~dB}$ (A) (Table III).

Overall, the Crossings on the National Highway exhibited minimum value of $L_{d}$ at Rehari crossing $(75.7 \mathrm{~dB} \mathrm{~A})$ on Sunday and maximum value at Jewel crossing $(88.2 \mathrm{~dB} A)$ on Monday. The minimum and maximum average $\mathrm{L}_{\mathrm{d}}$ was observed to be 78.2 and $86.4 \mathrm{~dB}$ (A) at Rehari and Jewel crossing respectively. While Crossings away from the National Highway exhibited minimum $\mathrm{L}_{\mathrm{d}}$ of $73.9 \mathrm{~dB}(\mathrm{~A})$ at Janipur crossing on Sunday and maximum $\mathrm{L}_{\mathrm{d}}$ of $91.9 \mathrm{~dB}$ (A) at Kachi Chawani crossing on Thursday. The minimum and maximum average $\mathrm{L}_{d}$ was observed to be 


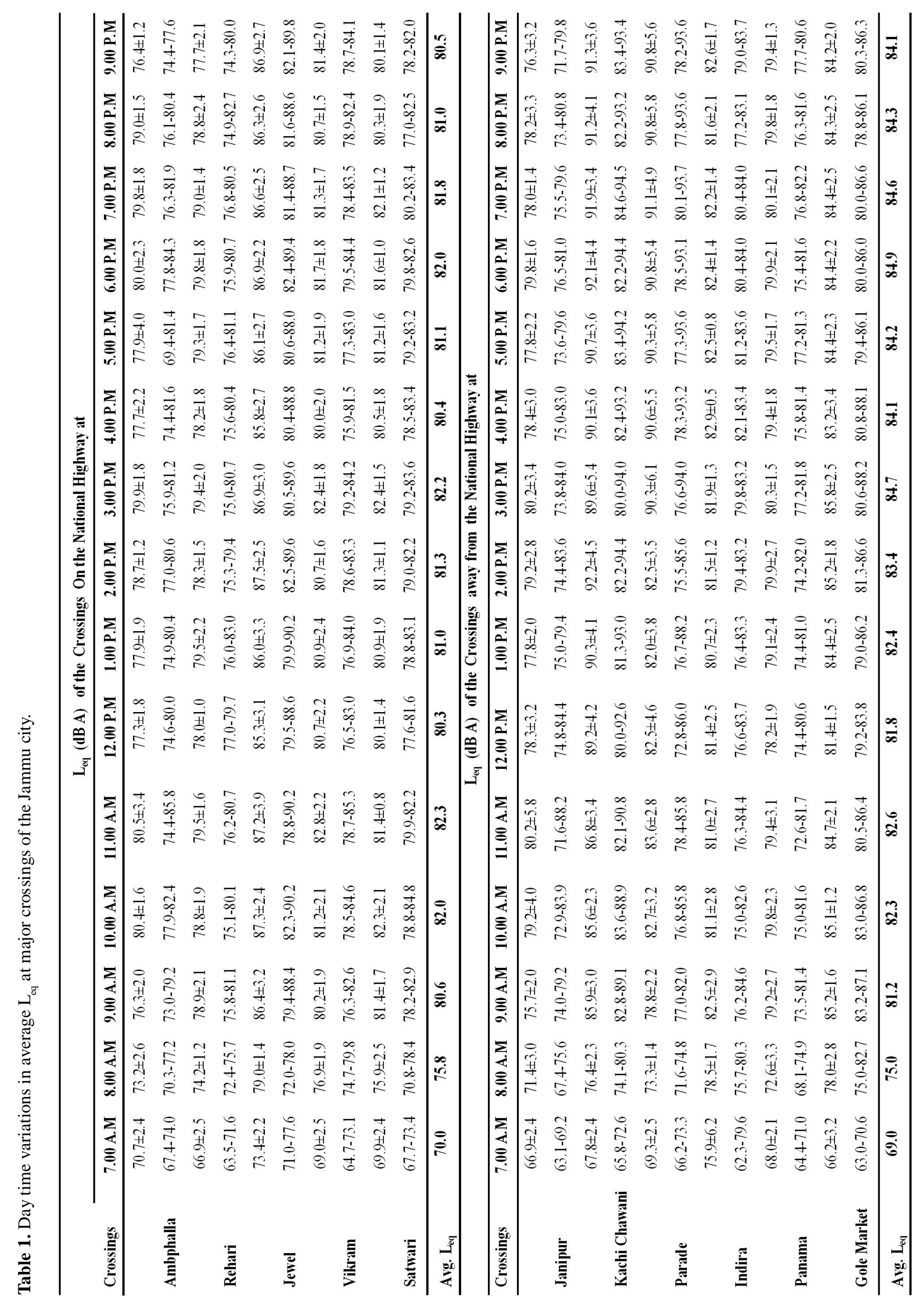




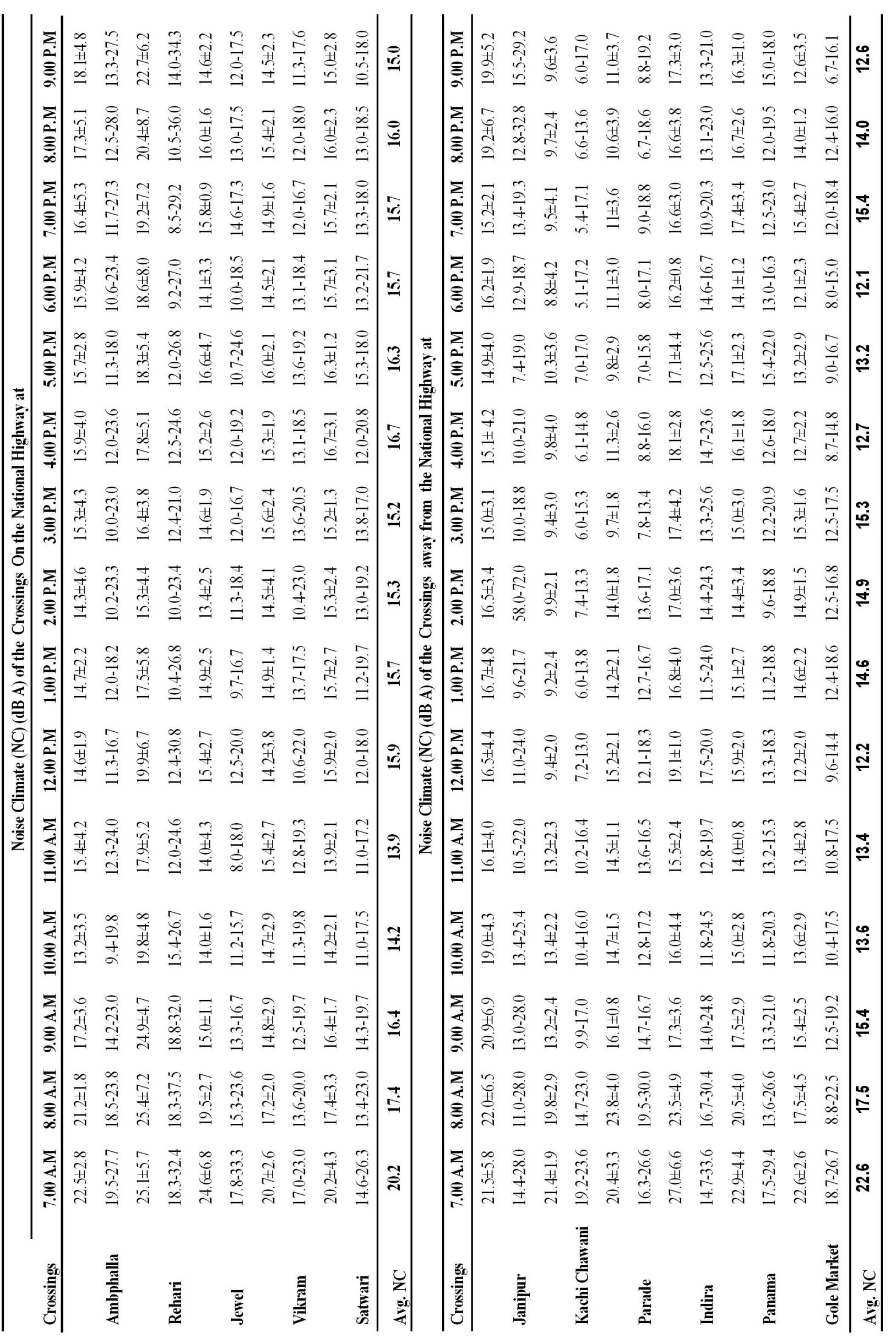




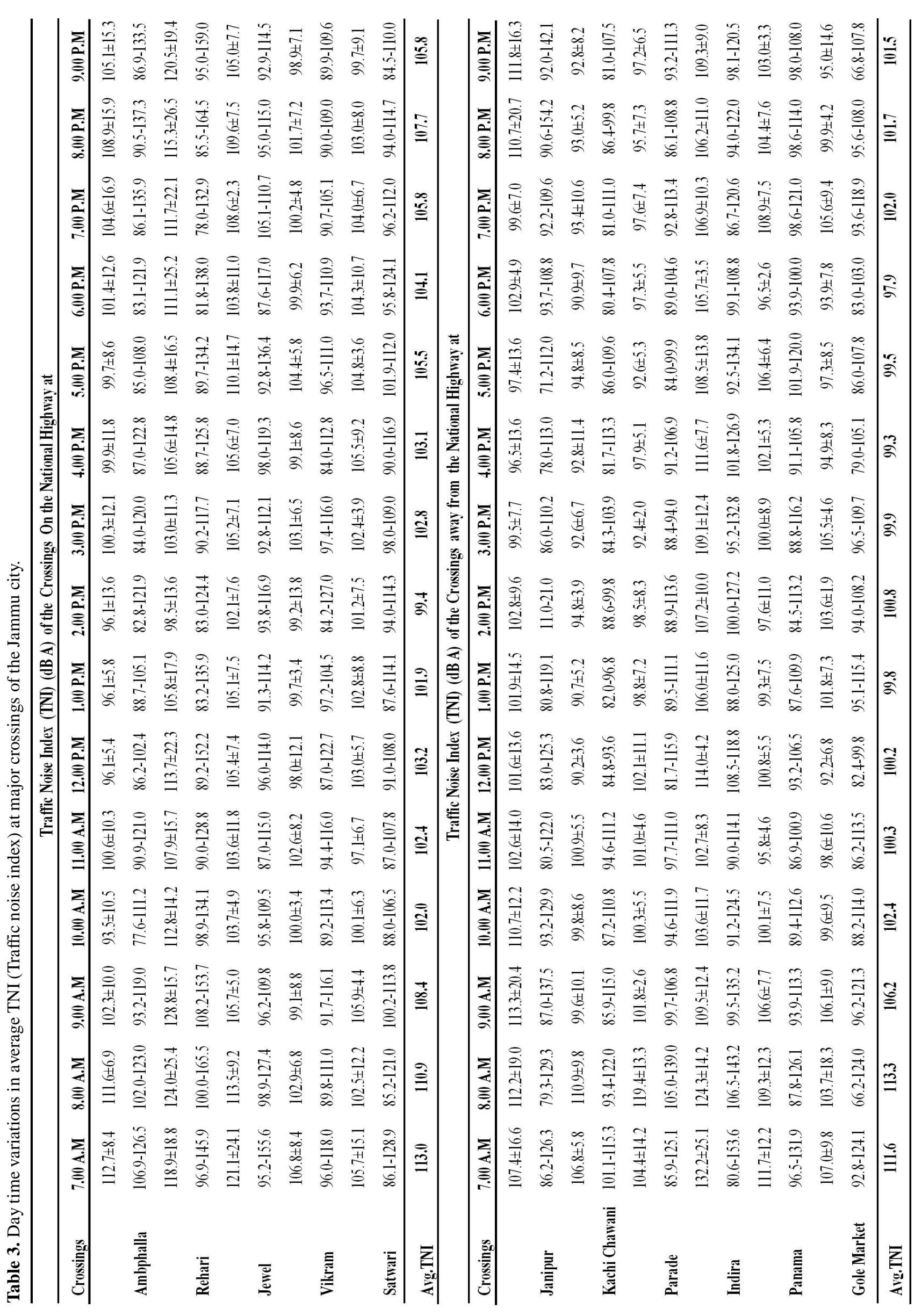




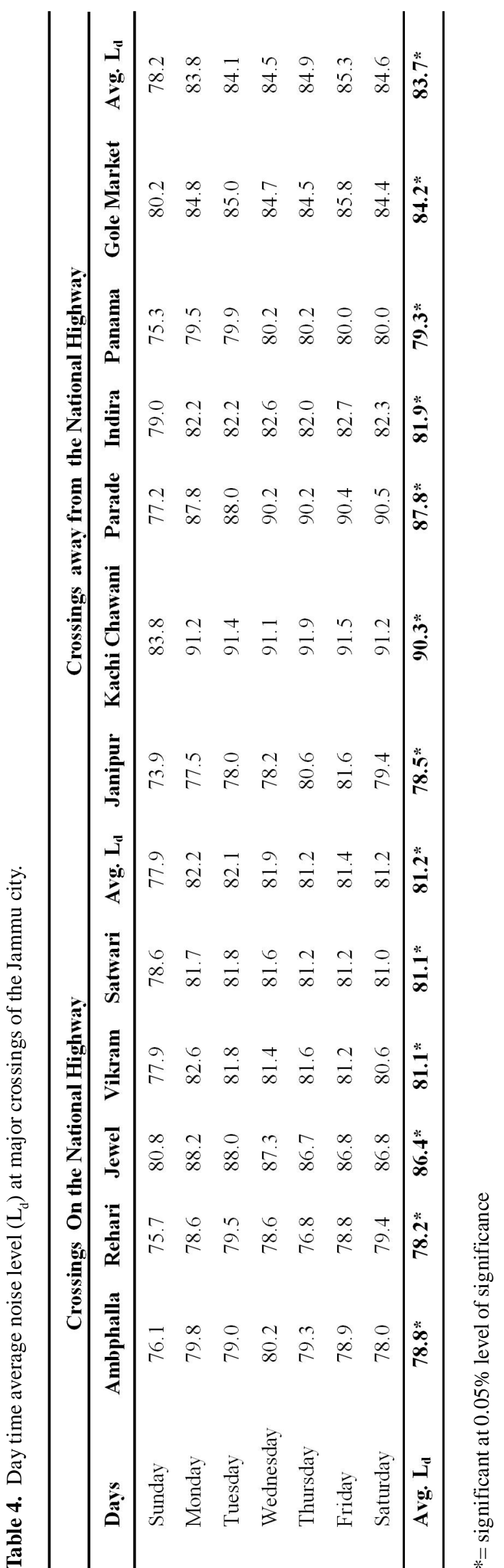

78.5 and $90.3 \mathrm{~dB}$ (A) at Janipur and Kachi Chawani crossing respectively. By applying One-way ANOVA using SPSS-17.0 the calculated value of $\mathrm{L}_{\mathrm{d}}$ at all the sites were observed to be statistically significant at $0.05(5 \%)$ level of significance $(\mathrm{p}=0.000-0.004)$ but values of Equivalent noise level $\left(\mathrm{L}_{\mathrm{eq}}\right)$, Noise climate (NC), Traffic noise index (TNI) were observed to be insignificant at $0.05(5 \%)$ So it can be concluded that all the crossings vary in the status of noise level due to variation in various attributes like traffic flow rate, degree of jams, commercial activity, location etc. which vary from crossing to crossing (Table IV). But all the values at all the crossings were above the prescribed limits of $65.0 \mathrm{~dB}(\mathrm{~A})$ and 55.0 $\mathrm{dB}(\mathrm{A})$ for commercial and residential areas respectively as given by Environment Protection Rules (1986) and set by Central Pollution Control Board.

Dhillon et al. (1994) in Ludhiana, Ravichandran et al. (1998) in Hosur (Tamilnadu), Das et al. (1999 ) in Jaipur, Pandya and Srivastva (1999) in Jabalpur, Raja et al . (1999) in Cuddalore (Tamlinadu), Ravichandran et al. (2000) in Puddukotai (Tamilnadu), Chakraborty et al. (2002) in Calcutta, Raina and Aggarwal (2003) in Jammu city, Mishra (2004) in Rewa town (M.P), Gangwar et al. (2006) in Barielly metropolitan city (U.P), Rao et al. (2007) in Vishakhapatnam city, Chauhan (2008) in Haridwar and Dehradun, Rampal and Pathania (2008) in Bishnah Town of Jammu, Rampal and Sharma (2008) in major road crossings of old Jammu city also observed the values of noise levels above the noise level values of commercial and residential areas as prescribed by Central Pollution Control Board. Srivastava and Dhabal (1998) also reported increased noise levels in commercial and residential buildings of Delhi and Calcutta due to traffic noise. Pandya and Srivastava (1999) and Gopalaswamy et al. (2002) also reported close relationship between volume of vehicles and noise level.

From overall analysis of the compiled data it can be concluded that average $\mathrm{L}_{\mathrm{d}}$ exhibited value of $81.1 \mathrm{~dB}(\mathrm{~A})$ at the crossing on National Highway and value of 83.7 $\mathrm{dB}(\mathrm{A})$ at crossing away from the National Highway and these values were found to be statistically significant at $0.05(5 \%)$ level of significance $(\mathrm{p}=0.000-0.002)$ by applying paired t-test using SPSS-17.0.Further critical analysis of the compiled data revealed that crossing on National Highway within the City exhibited average $L_{d}$ value of $82.2 \mathrm{~dB}(\mathrm{~A})$ and crossing on the National Highway at outskirts of City exhibited average $\mathrm{L}_{\mathrm{d}}$ value of $79.8 \mathrm{~dB}$ (A) and these values were also found to be statistically significant at $0.05(5 \%)$ level of significance $(\mathrm{p}=0.000$ 0.019 ) by applying paired t-test using SPSS-17.0.

\section{REFERENCES}

Ahmad, A.J. and Khan, J.A. (2003). Traffic Noise control in the city. NED Engineering Horizons, XVI: 174.

Chakraborty, D., Santra, S.C., Mukherjee, A.L., Roy, B. and 
Das, P. (2002). Road Traffic Noise in Calcutta metropolis, India. Ind. J . Environ. HIth., 3(1):173-180.

Chauhan, A. (2008). Study of noise pollution level in different places of Haridwar and Dehradun City (India). Environ. Consvn. J ournal, 9(3): 21-25.

Das, D.B., Bakra, P.P., Arya, P., Bhargava, A. and Gupta, A.S (1999). Environmental noise: Psychological, physiological and ambient assessment at industrial, residential and Commercial places of an urban area in Rajasthan. Ind. J . Env. Prot., 19 (7): 481-487.

Dhillon, M.K., Gupta, R. and Dhaliwal, G.S. (1994). Vehicular intensity and prediction of noise levels in rural and urban habitatawareness among house wives. Indian J . Ecol., 17(1): 13-16.

Gangwar, K.K., Joshi, B.D. and Swami, A. (2006). Noise pollution status at four selected intersections in commercial areas of Bareilly metropolitan city, U.P. H im. J. Env. Zool., 20(1): 75-77.

Gopalaswamy, V., Karthikeyan, S. and Ramamurthy, N. (2002). Predictions of Chidambaram town, Tamilnadu. Ind J. Env. Prot., 22(3): 322-326.

Mishra, B.K. (2004). Status and assessment of noise pollution level at Rewa town, M.P. J . C urr. Sci., 5(1): 623-628.

Pandya, M. amd Srivastava, R.K. (1999). Analysis of noise levels and its health effects in commercial areas of Jabalpur city: Part I of analysis of noise levels. Indian J . Env. Sciences,
3(2): 197-200

Raina, A.K., and Aggarwal, B. (2003). Assessment of noise levels in some areas of Jammu city. Nature Env. Pollution Technology, 2(4): 479-484.

Raja, R.E., Ravichandran, R.C. and Sagila, J.C. (1999). An assessment of noise pollution due to automobiles in Cuddalore, Tamilnadu. Ind. J. Environ. HIth., 41(4): 312316.

Rampal, R.K. and Pathania, D. (2008). Assessment of noise level in households of Bishnah town, Jammu (J\&K), India. Poll. Res., 27(1): 69-72.

Rampal, R.K. and Sharma, A. (2008). Noise levels in major road crossings of old Jammu city. Indian J. Environ. \& Ecoplan., 15(1-2): 161-166.

Rao, P.V., Murali, G., Sitaramaraju, S. and Srikanth, A. (2007). Monitoring of ambient air quality and noise pollution. Ind. J. Env. Prot., 27(10): 936-941.

Ravichandran, C., Chandrasekran, G. and Vijaya, M. (2000). Noise pollution assessment in Puddukotai (Tamilnadu). Poll. Res., 19(3): 431-434.

Ravichandran, C., Chandrasekran, G and Venkatasubramaniam, R. (1998). Status of noise pollution in Hosur (Tamilnadu). Ind. J . Env. Prot., 18(4): 278-280.

Srivastava, R.K.and Dhabal, R.L. (1998). Noise pollution in high rise buildings. J. Acoust. Soc. India, 26 (3 and 4): 11-14. 